\title{
POLITIKK
}

SKANDINAVISK TIDSSKRIFT

FOR INTERNASJONALE STUDIER

Årgang 78, Nummer 3, side 387-396, 2020, ISSN 1891-1757, www.tidsskriftet-ip.no, Publisert desember 2020

FoKUs: NÅR KRIG BLIR HVERDAG. MiLITARAKTIVISME I DE

SKANDINAVISKE LANDENES UTENRIKS- OG SIKKERHETSPOLITIKK

\section{Hvordan kan vi forstå skandinavisk militæraktivisme?}

\author{
Tormod Heier \\ Forsvarets høgskole, Norge
}

\begin{abstract}
Sammendrag
Siden Gulfkrigen i 1991 har skandinaviske land deltatt i nesten 30 år med sammenhengende krig, på blant annet Balkan, i Afghanistan, i Irak, Libya, Mali og Syria. Hvordan kan vi forstå denne formen for militæraktivisme? Tradisjonelle teorier fra realismen, institusjonalismen og konstruktivismen gir ingen gode svar. Innenfor organisasjonsteorien derimot, finnes det forklaringer knyttet til begrepet «strategisk kultur». Ved å utforske den strategiske kulturen i USAs militære styrker under krigene i Afghanistan, Irak og Libya trer det frem et tydelig mønster: det bombes for mye på militær side, og det snakkes for lite på diplomatisk side. I USAs doktriner levnes det lite til overs for dialog, forhandling og kompromiss. Dermed blir den strategiske kulturen innad i de militære styrkene et outrert uttrykk for en krigføringsform der operasjonene ses på som et null-sum spill. Resultatet blir oftest systemkollaps i statene som angripes. Denne kulturen har store konsekvenser for små skandinaviske allianseavhengige land: knappe forsvarsressurser trekkes inn i hengemyrerer det er vanskelig å komme ut av, ikke minst fordi koalisjonslederen selv, USA, forårsaker dem.
\end{abstract}

Nøkkelord: militæraktivisme $・$ kultur $・$ krig $・ U S A \bullet$ skandinavia

Skandinaviske land eksporterer militærmakt som aldri før. Fra å være blant de to mest skeptiske NATO-medlemmene under den kalde krigen, har Norge og Danmark gått i front når det gjelder bidrag til utenlandsoperasjoner på 1990- og 2000-tallet

\footnotetext{
^Kontaktinformasjon:Tormod Heier, e-post: hmo@diis.dk

(C2020 Tormod Heier. This is an Open Access article distributed under the terms of the Creative Commons Attribution 4.0 International License (http://creativecommons.org/licenses/by/4.0/), allowing third parties to copy and redistribute the material in any medium or format and to remix, transform, and build upon the material for any purpose, even commercially, provided the original work is properly cited and states its license.

Citation: Heier, T. (2020). Hvordan kan vi forstå skandinavisk militcraktivisme? Internasjonal Politikk, 78(3), 387-396. http://dx.doi.org/10.23865/intpol.v78.2469
} 


\section{Tormod Heier}

(de Carvalho \& Neumann, 2014; Jakobsen \& Rynning, 2019). Likeledes har svenske styrker, som under den kalde krigen holdt seg unna NATO, vært dypt involvert i vestlig koalisjonskrigføring; dels gjennom NATOs Partnerskap for fred-program på begynnelsen av 1990-tallet, og dels gjennom Alliansens operasjoner i Bosnia, Kosovo, Afghanistan, Irak og Libya (Møller \& Petersson, 2019). Siden Gulfkrigen i 1991 har dermed de skandinaviske landenes utenriks- og sikkerhetspolitikk vært preget av nesten 30 års sammenhengende krigføring. Hvordan kan vi forstå denne formen for militæraktivisme?

Å få mer kunnskap om dette fenomenet er viktig; særlig for skandinaviske land som, sammen med USA og NATO, ser ut til å tape flere kriger enn de vinner. Dette er ikke fordi soldatene er dårlig trent, eller lider store tap i møte med fienden. Snarere er det fordi skandinaviske styrker inngår i en bredere USA-ledet koalisjon som innledningsvis styrer mot seier, men som i overgangsfasen fra krig til fred - når det gjelder som mest - snubler. De militære suksessene gir ikke politiske resultater, verken i form av mer sikkerhet eller stabilitet i konfliktområdet. Eksempler på dette er krigene i Afghanistan, Irak og Libya. I stedet trekkes de skandinaviske styrkene inn i langvarige borgerkriger. Det er i denne overgangen at militæraktivismen oppstår; utallige kontingenter med skandinaviske soldater har i nærmere 20 år rotert inn og ut av konfliktområder der USA har ledet an i så vel Sentral-Asia som i Midtøsten. Mer kunnskap om hvordan koalisjonslederens krigføring bidrar til skandinavisk militæraktivisme er derfor påkrevd.

Denne kunnskapen er også viktig fordi militæraktivisme ute påvirker sikkerheten hjemme. Dette er ikke det samme som å si at all innsats ute gir mindre sikkerhet hjemme. For eksempel kan utenlandsoperasjoner tilføre norske, svenske og danske soldater mer kompetanse enn hva det er mulig å oppnå i Nord-Europa. Men når krig blir hverdagskost, fører det til et langvarig overforbruk av en knapp samfunnsressurs. Dette er et lite knippe styrker som også trengs for å avskrekke Russland i eget nærområde. Overforbruket har i mange år blitt underkommunisert fra myndighetenes side. Like fullt har slitasjen bidratt til å svekke landenes egen forsvarsevne, noe som igjen øker avhengigheten til USA og NATO. Dermed forrykkes landenes lavspenningspolitikk overfor Russland, fordi den skandinaviske forsvarsbufferen som under den kalde krigen holdt USA og Russland på en armlengdes avstand er borte (Brundtland, 1966; Heier, 2019, s. 87-105). I stedet har militæraktivismen ute skapt et vakuum hjemme. Ifølge den tidligere forsvarssjefen i Norge, admiral Haakon Bruun-Hanssen (2013-2020), fylles dette vakuumet av USA, samtidig som myndighetene selv «mister stadig mer råderett» (Lysberg, 2019).

\section{Militæraktivismens forklaringer}

For å forstå militæraktivisme som fenomen brukes ofte statsvitenskapelige skoleretninger. Her vil for eksempel realismen hevde at skandinaviske land sender styrker utenlands fordi de er avhengige av USA på hjemmebane (Walt, 1987). Det finnes 
nemlig ingen andre enn USA som kan gi Nord-Europa troverdige sikkerhetsgarantier i møte med Russland. Formaliserte medlemskap i NATO, slik Norge og Danmark har valgt, eller strategiske partnerskap slik Sverige har inngått, gir russiske randstater tilgang på amerikanske forsterkninger i tilfelle naboen i øst skulle true med krig. Men det betyr også at småstatene må akseptere en form for tilbakebetaling, blant annet ved å stille opp i kriger der det først og fremst er USA som har interesser (Snyder, 1984). Institusjonalismen forstår derimot skandinavisk militæraktivisme i lys av formalisert samarbeid i organisasjoner. For ettersom årene går, sosialiseres medlemsstatene inn i flernasjonale fellesskap. Lover, regler og konvensjoner blir til normative forventninger som alle medlemmene har interesse av å følge. Å gå til krig på vegne av fellesskapet blir innarbeidet praksis, sågar når eget territorium ikke trues. Men i kjølvannet av den kollektive solidaritetstankegangen senkes også terskelen for å gå til krig, fordi risiko- og byrdefordeling ute også skaper forventninger om resiprositet hjemme (Keohane, 1984). Dermed er veien kort til den tredje skoleretningen, konstruktivismen. Her tolkes militæraktivismen i lys av sosialt konstruerte normer og forestillinger. Politikere med ansvar for utenriks- og sikkerhetspolitikken i Oslo, Stockholm og København identifiserer seg selv med et større vestlig kulturfellesskap; i dette fellesskapet står det transatlantiske «selvet» i kontrast til «de andre» (Lipschutz, 1995; Neuman, 1996). Hva det vil si å være norsk, skandinavisk, europeisk eller demokratisk settes i relieff til terrorister, russere og IS-krigere; vi snakker om potensielle fiender som ikke deler den samme begeistringen for liberalt demokrati, universelle menneskerettigheter og grunnleggende rettsstatsprinsipper som oss selv. Når despoter dreper egen befolkning, eller går til krig mot andre land, blir det vanskelig å sitte med hendene i fanget. Å avstå fra organisert maktbruk blir synonymt med ansvarsfraskrivelse i kampen for den liberale, universelle verdiarven som FN, NATO og Vesten for øvrig bygger på. Da er det bedre, ifølge Storbritannias statsminister Tony Blair (1997-2007), å mønstre a force for good (Morris, 2002).

\section{Manglende forklaring}

Samlet sett gir de tre skoleretningene et dekkende bilde på hvorfor militæraktivisme har blitt hverdagskost i Skandinavia. Men teoriene forklarer ikke alt. For hvordan kan det ha seg at krigene ikke slutter? Hvorfor ender skandinaviske avdelinger opp i hengemyrer de ikke kommer ut av? Det er dette som fører til militæraktivisme, fordi soldatene ikke får vende hjem straks fienden er slått. I stedet må det utkjempes nye kriger, men da mot fiender som ikke lar seg nedkjempe militært, blant annet fordi motparten går i sivilt, holder sine våpen skjult, og fortsetter kampen i ly av sivilbefolkningen. Det er dette som skaper militæraktivisme, fordi skandinaviske soldater trekkes inn i kriger der motstanderen ikke lar seg nedkjempe raskt gjennom avgjørende slag. Realismen, institusjonalismen og konstruktivismen gir oss nyttig kunnskap for å forstå hvorfor skandinaviske land går til krig, isolert sett. Men teoriene sier lite om hvorfor skandinavisk utenriks- og sikkerhetspolitikk sakte, men sikkert 


\section{Tormod Heier}

militariseres, ettersom tusenvis av soldater - i tiår etter tiår - rullerer inn og ut av konfliktområdene i Sentral-Asia og Midtøsten.

Finnes det derfor andre årsaksforhold som kan belyse sammenhengen mellom måten det føres krig på, og skandinavisk militæraktivisme? I resten av artikkelen vil jeg bygge på forskningen til Jack L. Snyder (f. 1951), en amerikansk statsviter som er opptatt av hvordan strategisk kultur påvirker de skandinaviske landenes ubestridte koalisjonsleder, USA. Snyders utgangspunkt var spørsmålet om hvorfor ikke amerikanske styrker på 1970-tallet klarte å forutsi sovjetiske handlingsmønstre. Manglende klarsynthet skyltes, ifølge Snyder, at de militære avdelingene manglet evne til å se verden utenfra - med motpartens øyne. Konsekvensen var at offiserene i den militære kommandokjeden til stadighet ble overrasket hver gang sovjetiske styrker var involvert. I de fleste tilfeller tok nemlig sovjetiske motreaksjoner helt andre vendinger enn det amerikanerne selv forventet (Snyder, 1977).

Dette kan være et nyttig utgangspunkt for å søke mer kunnskap om hva som påvirker skandinavisk militæraktivisme. Grunnen er at de fleste utenlandsoperasjonene - som på Balkan, i Afghanistan, i Libya og i Irak - i all hovedsak planlegges, ledes og gjennomføres av amerikanske offiserer. Skandinaviske styrkebidrag er dessuten så få og så små at muligheten til å påvirke krigens gang, eller den strategiske kulturen som preger koalisjonsledelsen, er svært begrenset. Dermed blir det i all hovedsak amerikanske generaler og admiraler, samt amerikanske etterretningsorganisasjoner og forsvarsansatte i Pentagon, som setter premissene for krigens gang. Ifølge en annen norsk forsvarssjef vil norske - og skandinaviske - styrker alltid være for små til å ha reell innflytelse på det strategiske nivået der planene legges (Diesen, 2012). Det kan sågar stilles spørsmålstegn ved hvorvidt skandinaviske myndigheter, $\mathrm{i}$ hvert fall $\mathrm{i}$ Norge, i det hele tatt ønsker å påvirke krigens gang (Heier, 2019; Henriksen, 2013). «Å være med uten egentlig å være med» er et kjent credo i norsk strategisk tenkning (Skogrand \& Tamnes, 2001, s. 322). Strategisk kultur er imidlertid et vanskelig begrep. Før vi går videre, må vi derfor beskrive og konkretisere hva vi mener med uttrykket.

\section{Strategisk kultur}

I vår sammenheng forstås strategisk kultur som et sett av uskrevne normer, regler og forventninger rundt hva som er "passende adferd", særlig i organisasjoner eller profesjonsfellesskap der flere ansatte jobber sammen for å nå bestemte mål (March \& Olsen, 1994). Hva som er "passende adferd» bestemmes ut ifra hvilke ord, analogier eller metaforer som mer eller mindre ubevisst tas i bruk. Bruken er ofte institusjonalisert gjennom innlærte driller og prosedyrer. Over tid blir dette til mer eller mindre ubevisste, innarbeidede vaner, også i synet på hvordan kriger forstås, og hvordan kriger skal utkjempes (Snyder, 1977, s. 8). En ytterligere konkretisering vil være fremveksten av doktriner og standardprosedyrer for hvordan generaler og stabsoffiserer skal tenke operativt i en militær kontekst. Forventningene om hvordan krigen skal føres har ofte rot i tidligere hendelser - som «fødselsmerker» fra formative år i 
avdelingens tidligere historie. Det er dette, ifølge James Marsh og Johan P. Olsen (1989), som gir organisasjoner, enten de er sivile eller militære, en særegen identitet. I måten å forstå seg selv på, som kriger og offiser, skapes forventningene om hvordan kriger skal føres og fiender slås.

Denne kulturen preger stabsoffiserene på strategisk og operasjonelt nivå, så vel som de taktiske avdelingene nederst i kommandokjeden. Dermed blir strategisk kultur, ifølge Snyder, en viktig faktor som styrker offiserenes tro på militærmaktens autonomi og unike fortreffelighet. Perspektivet finner støtte i arbeidene til den amerikanske statsviteren Samuel Huntington (1927-2008), som hevdet at de bærende verdier i amerikansk forsvarstenkning bygger på en særegen identitet, et særlig ansvar for nasjonens overlevelse, og en unik ekspertise som skiller dem fra sivilsamfunnet for øvrig (Huntington, 1957, s. 59-79). Dette gjelder særlig i møtet med trusler som sivile myndigheter hverken har riktig materiell, trening eller kompetanse til selv å håndtere.

Redegjørelsen kan danne ansats til en empirisk forventning som kan hjelpe oss å forstå sammenhengen mellom amerikansk krigføring og skandinavisk militæraktivisme: nemlig at skandinaviske styrker blir involvert i kriger der koalisjonslederen først og fremst betrakter krigen som et militært, fremfor sivilt, anliggende. Det er med andre ord offiserene, og ikke diplomatene, som skal bestemme hvordan fienden skal slås. Dermed får tidligere innlærte doktriner og prosedyrer uforholdsmessig stor betydning for hva det vil si å innta en «passende adferd» overfor fienden. I den empiriske analysen vil vi nå se nærmere på dette årsaksforholdet, mellom «amerikansk krigføring» som uavhengig variabel og «skandinavisk militæraktivisme» som avhengig variabel. Som mellomliggende variabel ligger maktvakuumet som oppstår i kjølvannet av overdreven bombing fra koalisjonens side.

\section{Empirisk analyse}

I så vel Afghanistan (2001-2002) som i Irak (2003) og Libya (2011) fikk den amerikanske koalisjonsledelsen tilbud om våpenhvile og forhandlinger i krigenes innledende fase. I alle tilfellene valgte likevel de amerikanske myndighetene å fortsette krigen inntil motstanderen var nedkjempet militært. I Afghanistan førte dette til oppløsningen av Taliban-regimet. I Irak førte det til oppløsningen av Baath-partiet og landets væpnede styrker. I Libya førte det til drapet på statslederen Muammar al-Gaddafi, og støtte til en ny overgangsregjering. Denne korte oppsummeringen gir ikke et nyansert bilde av krigenes ulike hendelsesforløp. Men det er heller ikke poenget. For å finne svar på hvordan skandinavisk militæraktivisme kan forstås, holder det å synliggjøre mønsteret som trer frem: tilbudene som amerikanske myndigheter fikk om forhandlinger ble avslått; massive luftangrep mot motpartens lederskap og samfunnskritisk infrastruktur ble gjennomført; og statenes politiske styringsevne kollapset, mens nye og mer lydhøre regimer ble innsatt.

I ettertid ser vi klare tegn på at denne krigføringsmåten ikke førte frem. I så vel Afghanistan som i Irak og Libya ble det skapt uopprettelige maktvakuum. Dette 


\section{Tormod Heier}

skjedde blant annet fordi de politiske institusjonene som til daglig holdt anarki og lovløshet i sjakk, ble bombet sønder og sammen. Eksempler på dette er regjeringsbygninger, departementer og kommandosentraler, samt tele-, data- og elektrisitetsnettverk i de tre landenes hovedsteder. Tomrommet som oppstod ble senere fylt av uregjerlige stamme- og klanbaserte militser. Denne måten å føre krig på bidro med andre ord til langvarige borgerkriger etter at koalisjonsledelsen innledningsvis trodde at seieren var innkassert. I stedet for å forholde seg til en statlig motstander med politisk styring og kontroll over egne styrker, i en kommandokjede som ikke var lammet, ble så vel amerikanske som skandinaviske styrker konfrontert med hundrevis av uregjerlige militser. Alternativet som lå i en mer varsom tilnærming, der trusler om straff ble balansert med utsikter til belønning, ble ikke vurdert. En slik form for krigføring, som på fagspråket kalles tvangsdiplomati (George, 1991; Jakobsen, 1998; Schelling, 1967), var ikke en del av koalisjonenes operasjonskonsept eller plangrunnlag.

Dermed ble heller ikke de militære virkemidlene i tilstrekkelig grad knyttet opp til et bredere register av andre politiske virkemidler. Diplomatiske forsøk på dialog, forhandling og kompromiss, som et balanserende, modererende og utfyllende element til de militære straffetiltakene, forsvant. Det empiriske grunnlaget finner støtte fra flere hold. Ifølge den britiske strategen Lawrence Freedman, er amerikansk forsvarstenkning først og fremst preget av militær avskrekking og konvensjonell krigføring mot andre stater, som en "institusjonell arv» fra den kalde krigen (Freedman, 2003, s. 1). Dette synet finner også støtte blant noen av USAs fremste militærteoretikere på fagfeltet, som underviser USAs kommende generaler. Ifølge John Boyd og John A. Warden skal motparten først og fremst lammes, slik at militære avgjørelser kan oppnås så raskt og effektivt som mulig (Hammond, 2018; Warden, 1995, 2001). Den militærakademiske litteraturen understøttes også av teknologiske nyvinninger. Mer avanserte missiler, droner og jagerfly har utover på 1990- og 2000-tallet skapt en krigføringsform som legger enda mer vekt på høyt tempo, overveldende ildkraft og overraskelse (Keravuori, 2011; Kiras, 2006). I så vel amerikanske som allierte NATO-doktriner kommer dette klarest til uttrykk gjennom kraftfulle anslag mot statens lederskap, som ifølge koalisjonsledelsens operative planverk kalles for Centre of Gravity; dette er kraftsenteret der all motstand samordnes og styres fra (NATO, 2019). I Afghanistankrigen var dette mulla Muhammed Omar; i Irak var det Saddam Hussein (og senere IS-lederen al-Baghdadi og Iran-generalen Qassem Soleimani); i Libya var det Muammar al-Gadaffi. Dersom det ikke er mulig å ramme lederskapet direkte, skal såkalte Decisive Points rammes: viktige samfunnsfunksjoner som kraftsenteret er avhengig av, for eksempel militære kommando- og kontrollsystemer, sivile tele- og datasystemer, strømforsyning og logistikksystemer (NATO, 2019).

Det empiriske belegget, som er hentet fra forskningen, militærteorien, doktrinene og den teknologiske utviklingen, er i tråd med vår empiriske forventning: krigføring anses først og fremst som et militært - ikke et diplomatisk - anliggende. Bruk av militærmakt forstås, sett med amerikanske øyne, som en duell mellom to parter; en krig der "vinneren tar alt», og hvor motstanderen skal tvinges i kne gjennom en 
serie ydmykende nederlag. Det konkrete uttrykket for denne krigføringsformen finnes i amerikanske suksesskriterier som for eksempel decisive victory, overwhelming force og shock and awe (Ullmann et al., 2002). Prinsippene har i generasjoner blitt institusjonalisert nedover i USAs militære kommandokjede; dels gjennom sterke sosialiseringsprosesser i de respektive forsvarsgrenenes egne befals- og krigsskoleutdanning, der offiserene trenes og øves. Men også gjennom en lang rekke krigsspill, doktrinesamlinger og erfaringsseminarer, der nye generasjoner av stabsoffiserer og militære ledere læres opp i hva det vil si å være militær og føre krig. Ifølge den amerikanske generalen Wesley Clark, er ikke amerikanske styrker spesielt opptatt av en mer varsom eller gradert form for maktbruk: «In U.S. military thinking, we seek to be as decisive as possible once we begin to use force» (Clark, 2001, s. 449).

Å unngå utidig innblanding fra politikere, sivile embedsmenn og diplomater er snarere et uttrykk for Huntingtons militærfaglige autonomi, der USAs militære styrker opererer med store frihetsgrader i forhold til den politiske ledelsen og diplomatene i State Department. Med en særegen identitet, og med en sterk tro på egen organisasjons fortreffelighet, skal fienden nedkjempes på de militæres premisser. Det empiriske belegget for denne særegne kulturen finner blant annet støtte i uttalelsene til den amerikanske generalen Tommy Franks. Under planleggingen av operasjon Iraqi Freedom i 2003 utrykte han følgende i møte med den politiske forsvarsledelsen i Pentagon: «Keep Washington focused on policy and strategy. Leave me the hell alone to run the war» (Simpson, 2012, s. 141). Med denne formen for sivil-militær arbeidsdeling forsvinner imidlertid den strategiske koblingen mellom politiske mål og militære midler. For hver opprører som drepes, skapes i stedet ti nye (Aase, 2015). Resultatet kan derfor fort bli, slik Emile Simpson beskrev den vestlige koalisjonskrigføringen i Afghanistan, at «there was no strategy that united the military and the civilian; [...] a wider awareness of where the war was going was excluded» (Simpson, 2012, s. 141). Bekymringene rundt lite sivil-militær samordning, og en altfor fiendefokusert opprørsbekjempning, ble også understreket av den amerikanske generalen Michael T. Flynn, som ledet ISAF i krigen mot Taliban i 2008-2010:

\footnotetext{
Eight years into the war in Afghanistan, the U.S. intelligence community is only marginally relevant to the overall strategy. Having focused the overwhelming majority of its collection efforts and analytic brain-power on insurgent groups, the vast intelligence apparatus is unable to answer fundamental questions about the environment in which U.S. and allied forces operate and the people they seek to persuade. (Flynn et al., 2010, s. 7)
}

Tvangsdiplomatiet som forsøker å kombinere trusler om straff med utsikter til belønning - balansen mellom gulrot og pisk - blir, sett med amerikanske øyne, i stedet betraktet som et internt, militærfaglig anliggende. Disse forventningene synes også å være dypt institusjonalisert i den amerikanske forsvarstradisjon. Sporene kan blant annet føres tilbake til den såkalte Powell-Weinbergerdoktrinen fra 1982. I kjølvannet av det ydmykende nederlaget i Vietnamkrigen skulle amerikanske styrker 


\section{Tormod Heier}

vende tilbake til tradisjonelle kjerneoppgaver: to win the nation's war. Dette forutsatte klare politiske sluttilstander, militærfaglig autonomi i måten krigen ble ført på, og overveldende ildkraft - helst mot konvensjonelle statelige styrker som i grovt var trent og utrustet som en selv (Middup, 2011).

\section{Avslutning}

I denne artikkelen stilte vi spørsmålet om hvordan skandinavisk militæraktivisme kan forstås. Med utgangspunkt i den strategiske kulturen som preger amerikanske styrker, og en empirisk forventning om at fienden først og fremst skal nedkjempes militært, kan vi utlede følgende slutning: Skandinavisk militæraktivisme kan forstås som et uttrykk for en rekke mislykkede kriger der USA-ledede koalisjonsoperasjoner har skapt et maktvakuum i statene som har blitt angrepet. I dette maktvakuumet har deretter skandinaviske styrker blitt stående i tiår etter tiår, uten mulighet til å trekke seg ut - med mindre de ønsker å bli «gratispassasjer» i det vestlige sikkerhetsfellesskapet de selv er avhengige av på hjemmebane.

Amerikanske strategier i Sentral-Asia, Midtøsten og Afrika legger først og fremst vekt på sine egne komparative fortrinn i møtet med fienden. Så lenge ingen andre kan måle seg med USAs militære styrke, blir naturlig nok dette virkemiddelet mest brukt sammenlignet med tvangsdiplomatiets «mykere» vektlegging av dialog, forhandling og kompromiss.

Den strategiske kulturen som preger USAs væpnede styrker får dermed en uforholdsmessig stor plass i måten USA-ledede koalisjoner fører krigene sine på. Planleggings- og beslutningsprosessene som styrer de taktiske styrkebidragene fra skandinaviske land vil i all hovedsak være påvirket av amerikanske generaler, admiraler og etterretningsorganisasjoner som, i tråd med innarbeidede normer, regler og forventninger til hvordan kriger skal føres, får et uforholdsmessig stort handlingsrom.

\section{Om forfatteren}

Tormod Heier er oberstløytnant, forskningsleder og professor ved Forsvarets høgskole i Oslo. Han har tidligere jobbet i blant annet Etterretningstjenesten, Forsvarsdepartementet og i Afghanistan. Han har redigert en rekke antologier om norsk og europeisk forsvars- og sikkerhetspolitikk. Hans siste bok heter Et farligere Norge? (Bergen: Fagbokforlaget, 2019).

\section{Litteratur}

Aase, V. T. (2015, 6. desember). På dagen styrte de USAs droner mot terror, på kvelden drakk de te og tok narkotika. Aftenposten. Hentet fra https://www.aftenposten.no/a-magasinet/i/7Vg3/paa-dagen-styrte-deusas-droner-mot-terror-paa-kvelden-drakk-de-og-tok-narkotika

Brundtland, A. O. (1966). The Nordic balance. Past and present. Cooperation and Conflict, 1(4), 30-63. https:// doi.org/10.1177\%2F001083676600100403 


\section{Hvordan kan vi forstå skandinavisk militceraktivisme?}

Clark, W. K. (2001). Waging modern war. New York: Public Affairs.

de Carvalho, B. \& Neumann, I. B. (Red.). (2014). Small state status seeking. Norway's quest for international standing. London: Routledge.

Diesen, S. (2012). Hva er militærstrategi? - Har vi behov for slik tenkning i Norge? I T. E. Sæveraas \& V. L. Owesen (Red.), Norsk luftmakt over Libya - suksess uten innflytelse? Luftkrigsskolens skriftserie, 27(1), 37-47.

Flynn, M. T., Pottinger, M. \& Batchelor, P. (2010). Fixing Intel: A blueprint for making intelligence relevant in Afghanistan. Washington, DC: Center for a New American Security. Hentet fra http://online.wsj.com/ public/resources/documents/AfghanistanMGFlynn_Jan2010.pdf.

Freedman, L. (Red.). (2003). Strategic coercion. Concepts and cases. Oxford: Oxford University Press.

George, A. L. (1991). Avoiding war. Problems of crisis management. Boulder, CO: Westview Press.

Hammond, G. T. (2012). The mind of war. fohn Boyd and American security. New York: Smithsonian Institution.

Heier, T. (2019). Hadde norske myndigheter kontroll i Libya-krigen? I T. Heier, T. Tvedt \& R Ottosen (Red.), Libya: Krigens uutholdelige letthet (s. 71-91). Oslo: Cappelen Damm.

Heier, T. (2019). Et farligere Norge? Oslo: Fagbokforlaget.

Henriksen, D. (2013). Suksess uten innflytelse? Norges erfaringer fra operasjonene over Libya. Internasjonal Politikk, 71(1), 29-56. Hentet fra https://www.idunn.no/ip/2013/01/suksess_uten_innflytelse_-_norges_ erfaringer_fra_operasjon

Huntington, S. (1957). The soldier and the state, the theory and politics of civil-military relations. Cambridge, MA: The Belknap Press.

Jakobsen, P. V. (1998). Western use of diplomacy after the Cold War: A challenge for theory and practice. London: Macmillan Press Ltd.

Jakobsen, P. V. \& Rynning, S. (2019). Happy to fight, will travel. International Affairs, 95(4), 877-895. https:// doi.org/10.1093/ia/iiz052

Keohane, R. O. (1984). After hegemony. Cooperation and discord in the world political economy. Princeton, NJ: Princeton University Press.

Keravuori, R. L. (2011, 17. november). Lost in translation: The American way of war. Small Wars fournal. Hentet fra https://smallwarsjournal.com/jrnl/art/lost-in-translation-the-american-way-of-war

Kiras, J. D. (2006). Special operations and strategy: From World War II to the War on Terrorism. New York: Routledge.

Lipschutz, R. D. (Red.) (1995). On security. New York: Columbia University Press.

Lysberg, M. (2019, 19. august). - Vi kan miste råderetten. Klassekampen. Hentet fra https://www.klassekampen. no/article/20190819/ARTICLE/190819967

March, J. G. \& Olsen, J. P. (1989). Rediscovering institutions: The organizational basis of politics. New York: The Free Press.

March, J. G. \& Olsen, J. P. (1994). A primer on decision making. New York: The Free Press.

Middup, L. F. (2011). The legacy of Vietnam and the Powell doctrine: Four case studies (Doktorgradsavhandling, Universitetet i Nottingham). Hentet fra http://citeseerx.ist.psu.edu/viewdoc/download;jsessionid= 0E4A7A3480FB33240980F47F0ACF0A22?doi=10.1.1.475.9270\&rep=rep 1\&type=pdf

Morris, N. (2002, 5. januar). Britain to act as 'force for good' says Blair. The Independent. Hentet fra https:// www.independent.co.uk/news/world/asia/britain-to-act-as-force-for-good-says-blair-9131269.html

Møller, J. E. \& Petersson, M. (2019). Sweden, Finland, and the defence of the Nordic-Baltic region - ways of British leadership. I R. Johnson \& J. H. Matlary (Red.), The United Kingdom's defence after Brexit. Britain's alliances, coalitions, E partnerships (s. 215-243). London: Palgrave Macmillan.

NATO. (2019). Allied joint doctrine for the conduct of operations. Nato Standardization Office. Hentet fra https://assets.publishing.service.gov.uk/government/uploads/system/uploads/attachment_data/file/ 797323/doctrine_nato_conduct_of_ops_ajp_3.pdf

Neumann, I. B. (1996). Russia and the idea of Europe. A study in identity and international relations. London: Routledge.

Simpson, E. (2012). War from the ground up. Twenty-first century combat as politics. London: Hurst \& Co.

Skogrand, K. \& Tamnes, R. (2001). Fryktens likevekt. Atombomben, Norge og verden, 1945-1970. Oslo: Universitetsforlaget.

Snyder, G. H. (1984). The security dilemma in alliance politics. World Politics, 36(4), 461-495. https://doi. org/10.2307/2010183

Snyder, J. L. (1977). The Soviet strategic culture: Implications for limited nuclear operations. Santa Barbara, CA: Rand Corporations. 


\section{Tormod Heier}

Ullman, H., Wade Jr, J., Edney. L. A., Franks, F. Jr., Horner, C., Howe, J. \& Brendly, K. (2002). Shock and awe: Achieving rapid dominance. Washington, DC: National Defense University Press.

Walt, K. (1987). The origin of alliances. Ithaca, NY: Cornwell University Press.

Warden, J. (1995). The enemy as a system. Air and Space Power Fournal, 9(1), 40-55. Hentet fra http://www. airpower.maxwell.af.mil/airchronicles/apj/apj95/spr95_files/warden.htm

Warden, J. (2001). Winning in fast time: Harness the competitive advantage of Prometheus in business and life. Boca Raton, FL: Geo Group Press.

\section{Abstract in English \\ How Should Scandinavian Military Activism Be Understand?}

Since the 1991 GulfWar, Scandinavian states have continuously been engaged in various international operations, i.e. on the Balkans, in Afghanistan, in Iraq, Libya, Mali and Syria. How can we comprehend this peculiar form of Scandinavian military activism? Traditional theories derived from realism, institutionalism and constructivism provides few convincing explanations. Within organisational theory however, plausible explanations may be found though the concept of 'strategic culture'. By exploring the military culture prevailing inside US forces operating in Afghanistan, Iraq and Libya, a consistent pattern arises: too much bombing from the military side, coupled with insufficient diplomatic talks. Little effort is paid to dialogue, negotiations and compromises. US warfighting thereby becomes a one-dimensional expression of a zero-sum game where the winner takes it all. The result is a collapse inside the states that are attacked. This culture has grave consequences for small Scandinavian allies: scarce military resources are trapped into a quagmire made by the coalition leader itself, the United States.

Keywords: military activism $\bullet$ culture $\cdot$ war $\bullet$ USA $\bullet$ Scandinavia 